\title{
Assessment of social vulnerability against disasters: a pilot case for an earthquake in Istanbul
}

\author{
B. Ergün Konukcu, E. Y. Menteşe \& O. Kılıç \\ Directorate of Earthquake and Ground Research, \\ Istanbul Metropolitan Municipality, Turkey
}

\begin{abstract}
According to the United Nations Office for Disaster Risk Reduction (UNISDR), disasters are events which cause physical, economic and environmental losses and effects that exceed the coping capacity of societies and harm their functionality. The most apparent results of the disasters are physical such as building or lifeline damage and loss of lives. It is also known that the social components of society are also under threat and the loss of these values can increase the physical impacts of disasters causing cascading effects. Social vulnerability is defined as "the characteristics of a person or group and their situation that influence their capacity to anticipate, cope with, resist and recover from the impact of a natural hazard".

With this study, we aim to develop an ex-ante assessment model to understand social vulnerability against disasters. The model depends on indicators and their interrelation with each other. The basic idea behind the indicator selection has been to grasp where the level of fragility is high and the level of resilience is low against disasters. A pilot study covering 50 subdistricts of Istanbul is carried out to obtain data for quantification of the indicators (demographical, economical, disability, health, community preparedness and mobility). To improve the data resolution; 8000 samples (households) are selected to represent each subdistrict. As a result of the analysis, 50 sub-districts are compared to each other based on an Analytical Hierarchy Process according to their level of social vulnerability.

Keywords: social vulnerability, social survey, earthquake, Istanbul, resilience.
\end{abstract}




\section{Introduction}

While the most apparent results of the disasters are physical, such as building or infrastructure damage and loss of lives; it is also known that social components of society are also under threat and the loss of these values can increase the physical impacts of disasters causing cascading effects. Social vulnerability is defined as "the characteristics of a person or group and their situation that influence their capacity to anticipate, cope with, resist and recover from the impact of a natural hazard" (Wisner et al. [1]).

The definition above implies that social vulnerability is affected by inherent factors of fragility of a person or group (i.e. personal attributes, living situations and finances). At the same time, it is implied that overcoming vulnerability (that is building capacity in the face of hazards) requires factors of resilience, such as an available means of disaster preparedness and risk mitigation, solidarity and social networks, savings and other buffers and resources for reconstruction and recovery. Thus, if there is a lack of resiliency against disasters, it will increase the vulnerability.

In this study, the purpose is to develop an assessment model to understand social vulnerability against disasters. In this frame, because of its earthquake susceptibility, Istanbul is used as a pilot case.

As method, we used an indicator based ex-ante vulnerability analysis approach. In other words, we acknowledge that the circumstances that can increase the level of social vulnerability are already known. Thus, we determined the indicators depending on a detailed literature review and expert views through iterative meetings. The basic idea behind the indicator selection has been to grasp where the level of fragility is high and level of resilience is lacking. Based on the aforementioned process, these indicators are assumed to help us understand and define social vulnerability. Thereafter, a detailed survey is carried out on 8000 households; covering the pilot area consisting of 50 subdistricts of Istanbul to gather required data for indicators. Lastly, these indicators are assessed through an Analytical Hierarchy Process to give weight to the indicators and relatively rank the sub-districts based on their level of social vulnerability. The project time for this pilot project was 9 months and the survey took 4 months.

\section{Method}

There are three parts of the methodology: determination of social vulnerability indicators, data aggregation (survey) and social vulnerability analysis.

\subsection{Determination of social vulnerability indicators}

At the end of the literature review and expert reviews, social vulnerability indicators are determined as follows. Demographic structure of households (age, number of people), economic structure (employment, debt status, saving status, income status, property ownership, wealth status, social security), disability and 
special treatment needs (disability (physical - mental), special treatment needs, elderly in need of care), education status (recently graduated school), access to health service (social security, private health insurance, proximity health facility), community preparedness (risk perception, household-based risk reduction, neighborhood-based risk reduction, solidarity) and mobility (motor vehicle ownership, disabled, special treatment needs, elderly in need of care, host state outside of earthquake, the possibility of meeting the household).

\subsection{Survey}

A survey was conducted to provide the necessary data for social vulnerability analysis. In this scope, the survey was conducted by ETIK Field Research Company in 50 pilot sub-districts at 8 districts based on 8000 households. We gathered the address information of these households from the TUIK (Turkish Statistical Institute) by random sampling. In addition to this, in depth interviews were made with 48 of the 50 sub-district chief officers (muhtar).

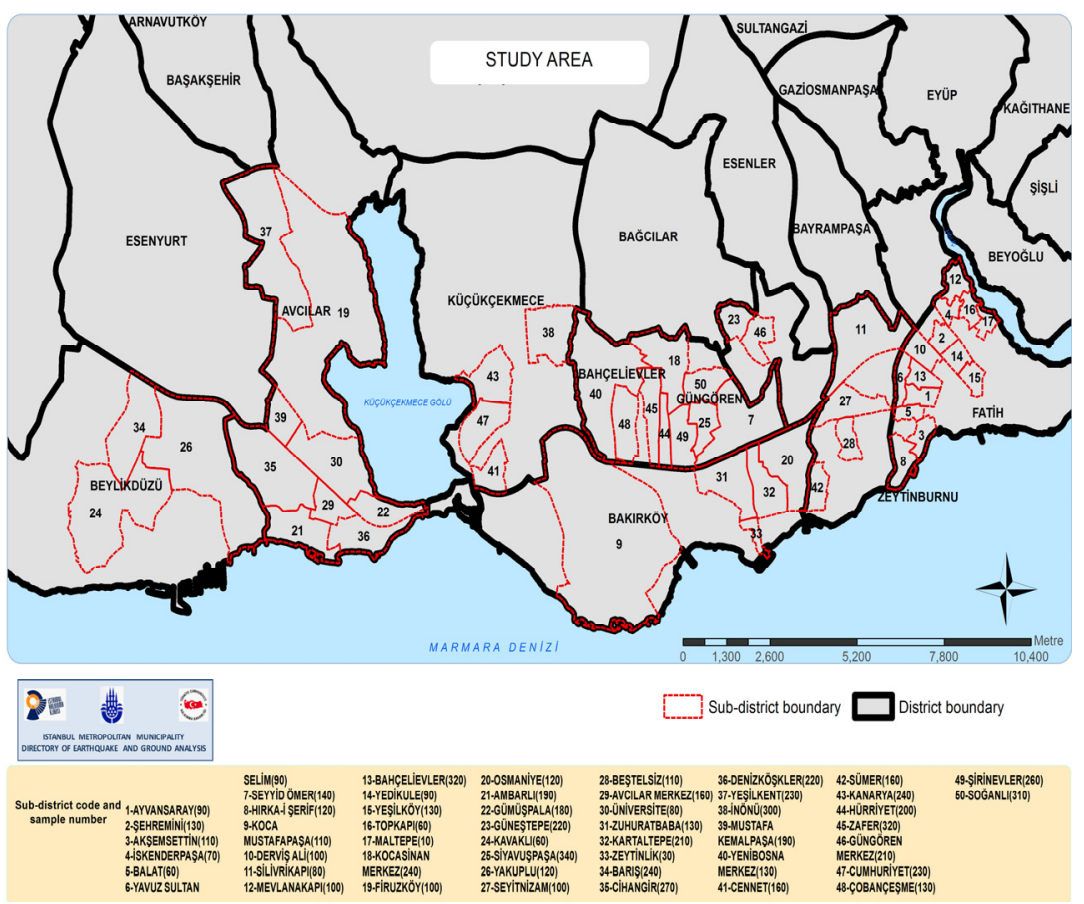

Figure 1: Study area.

We prepared the questionnaire in consultation with Prof. Sibel Kalaycioğlu (sociology) from Middle Technical University, Assoc. Prof. Burçay Erus (economics), Prof. Eser Çaktı (earthquake engineering) and Bilgen Sungay (disaster risk management) from Bosphorus University. After several iterating 
consultative meetings, 56 questions were agreed on to take place in the survey and 25 questions took place in an in depth interview with sub-district chief officers. The interviews were made in a descriptive manner rather than quantitative. The basic idea behind the interviews was to obtain the ideas of the officers about their neighborhoods and their level of perception, preparation and willingness to reduce earthquake risks.

In the household survey from each house a member of the family was chosen (older than 18 years) who could represent or at least had enough knowledge about the residents. The age distribution of the interviewed people in 8000 households is shown in fig. 2 .

Approximately $43 \%$ of the subjects are mothers while $29 \%$ are fathers.

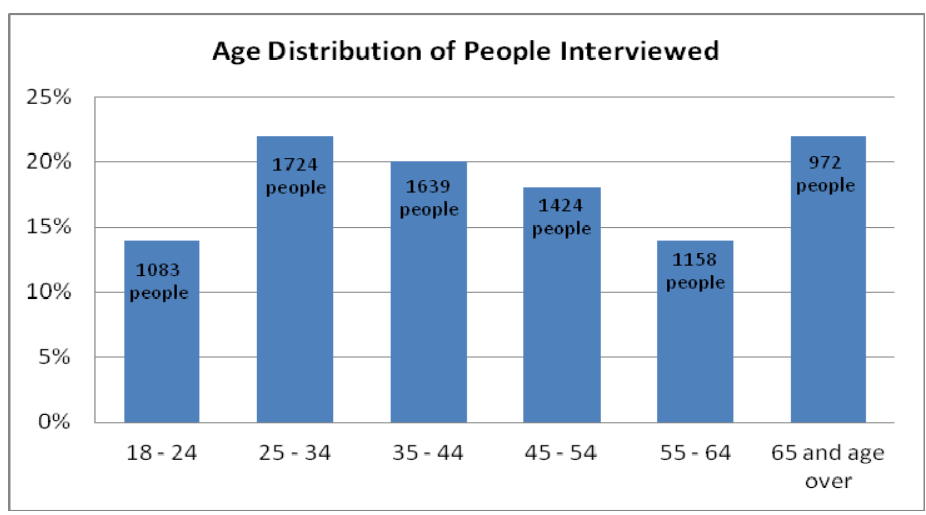

Figure 2: Age distribution of the people interviewed.

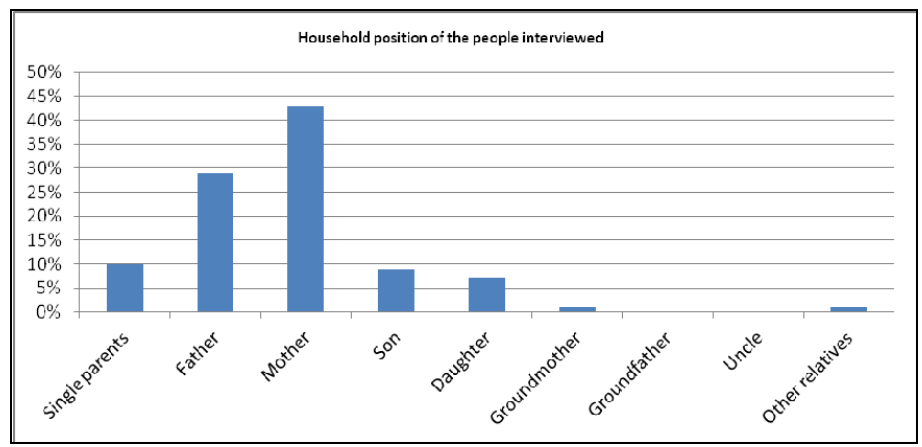

Figure 3: Household position of the people interviewed.

\subsubsection{Findings on household structure}

When the gender distribution of those households was analyzed, we observed that male and female rates are almost same (49.9\% male; $50.1 \%$ female).

One of the important data on individual household is the age distribution within the concept of social vulnerability. It is known that the dependent population groups especially (by means of age) in a household increases the 
social vulnerability (Cutter et al. [2]). The Turkish Statistical Institute defines dependent population as persons younger than 14 and over 65 years of age. The rate of persons younger than 14 years is $14.5 \%$ and the rate of over 65 years is $8.3 \%$ in this study.

There is a direct proportional relationship between the number of people in a household and social vulnerability. It is also observed that fragility increases as the number of people increase in a household. Survey results show that, the rate of single parents is very low $(3.2 \%)$ and the majority of the research group lives as nuclear family.

Table 1: Number of people in a household.

\begin{tabular}{|c|c|c|}
\hline $\begin{array}{c}\text { Number of people in a } \\
\text { household }\end{array}$ & $\begin{array}{c}\text { Number of total } \\
\text { households }\end{array}$ & Percentage \\
\hline 1 & 834 & $10.43 \%$ \\
\hline 2 & 2055 & $25.69 \%$ \\
\hline 3 & 2129 & $26.61 \%$ \\
\hline 4 & 1768 & $22.10 \%$ \\
\hline 5 & 819 & $10.24 \%$ \\
\hline 6 & 263 & $3.29 \%$ \\
\hline 7 & 82 & $1.03 \%$ \\
\hline 8 & 28 & $0.35 \%$ \\
\hline 9 & 11 & $0.14 \%$ \\
\hline 10 & 8 & $0.10 \%$ \\
\hline 11 & 2 & $0.03 \%$ \\
\hline 12 & 1 & $0.01 \%$ \\
\hline & 8000 & $100 \%$ \\
\hline
\end{tabular}

\subsubsection{Disability and special treatment needs}

Groups with special needs in terms of health (patient, physical and/or mental disability) are more affected by social vulnerability (Evans and Kantrowitz [3]). The rate of physical/mental disability in research is $0.8 \%$.

There may be problems in accessing specialized medical equipment needs after a potential earthquake. For this reason, we investigated the need for special medical treatment. The rate of people who have chronic diseases seems relatively high $(16.4 \%)$ and 417 people in households need special treatment. The most common diseases in the research group are diabetes, blood pressure, physical therapy and cardiovascular disease with the rate of $60 \%$.

Table 2: Is there a case for special treatment?

\begin{tabular}{|c|c|}
\hline Answers & Percentage \\
\hline Yes & $3.03 \%$ \\
\hline No & $96.95 \%$ \\
\hline I do not know & $0.02 \%$ \\
\hline
\end{tabular}


Generally, people below 14 years of age and over 65 are more fragile than other age groups. If there are cases of people being both over 65 years old and in need of care in a household, we assumed that fragility would increase much more. When the results are analyzed in this respect, the percentage of the elderly population in need of care is $0.7 \%$.

\subsubsection{Access to health service}

The high access to health services is very important to make for appropriate treatment and eliminate injury immediately after a disaster. Under this topic, we assessed social security, private health insurance and the accessibility of health facilities.

$18.1 \%$ of the subjects have no social security. After an earthquake it would be difficult to return to the old standard of living because of this state of insecurity. $6.9 \%$ of the search group belongs to BAĞKUR (Social Security Organization for Artisans and the Self-Employed). It is assumed that this group is fragile because of the fact that they are self-dependent and in a possible loss of their jobs they may lose most of their work ability and wellbeing.

In the case of private health insurance, it has been observed that a very low level $(1.6 \%)$ of households has this type of insurance. On the other hand, the entire study group (99\%) reported that there is a health facility within walking distance of their homes. Accessibility of health facilities by walking is an important indicator because of the earthquake induced road blockage that may limit vehicle access. The most common answer given to the nearest health facility is "primary health care center" with the rate of $47.10 \%$. But it must be considered that "primary health care center" is closed after $5 \mathrm{pm}$ and on weekends. Also "primary health care centers" do not have sufficient equipment for complex treatment. Because of this situation, fragility could be increased.

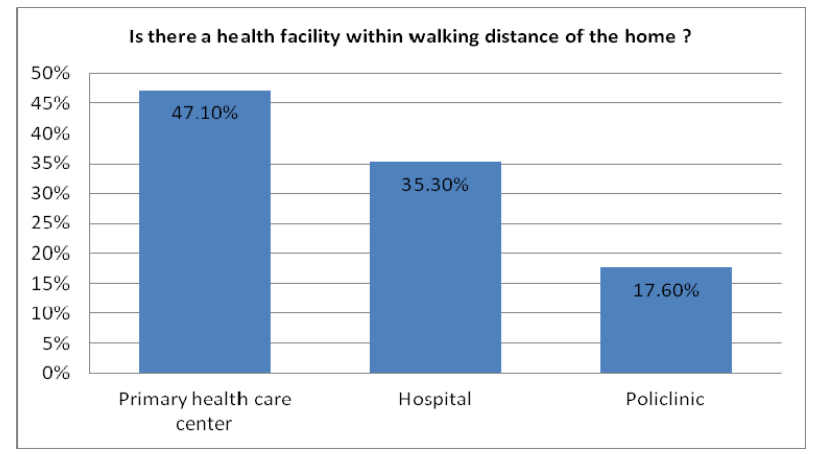

Figure 4: Health facility status.

\subsubsection{Education status}

The educational level of subjects are as follows: 3.3\%: illiterate, $1.8 \%$ : literate, 1.6\%: primary school, 24.4\%: graduated elementary school in the research group. On the other hand, one out of every 10 people who participated in the survey seems to be a university graduate. It is observed that the awareness of 
disasters (earthquake insurance, earthquake resistant home, etc.) increases proportionally with level of education. It can be assumed that as the level of education increases; social vulnerability decreases.

\subsubsection{Economic status}

One of the important factors that determine ability to cope with the negative effects of the earthquake is the economic status of households. In order to determine the economic situation of households, questions were asked on income, income source, accumulation and debt. 6950 households out of 8000 answered the income questions.

Table 3: What is the total income of your home?

\begin{tabular}{|l|c|c|}
\hline & Frequency (n) & Percentage \\
\hline Under 500 TL & 149 & $1.9 \%$ \\
\hline $500-1000 \mathrm{TL}$ & 905 & $11.3 \%$ \\
\hline $1001-1500 \mathrm{TL}$ & 1772 & $22.2 \%$ \\
\hline $1501-2000 \mathrm{TL}$ & 1712 & $21.4 \%$ \\
\hline $2001-3000 \mathrm{TL}$ & 1444 & $18.1 \%$ \\
\hline $3001-4000 \mathrm{TL}$ & 576 & $7.2 \%$ \\
\hline $4001-5000 \mathrm{TL}$ & 235 & $2.9 \%$ \\
\hline $5001-7500 \mathrm{TL}$ & 114 & $1.4 \%$ \\
\hline $7501-10000 \mathrm{TL}$ & 22 & $0.3 \%$ \\
\hline Over 10000 TL & 21 & $0.3 \%$ \\
\hline No idea, refused & 1050 & $13.1 \%$ \\
\hline Total & 8000 & $100.0 \%$ \\
\hline
\end{tabular}

The proportion of households with income below the poverty level is quite high. Nearly one out of every five households belongs to a low-income group. $74 \%$ of income is salary according to survey data. In $58.26 \%$ of households, the only income source is income from employment. $12.80 \%$ of households with retirement income and in $3.12 \%$ of households, rents, interest or subsidy are the types of supplies. $4.43 \%$ of the households get help from the public or private sector.

The most important factors that could create fragilities are unregistered (illegal) employment. Workers in these jobs are deprived of social security. According to the survey data, 473 households are not within the scope of social insurance.

Unemployed people in a household are an important factor for determining the size of the effects of an earthquake. The rate of unemployed people is $5.66 \%$. In the research group there are lots of people long term unemployed, which is assumed to increase social vulnerability.

$21.9 \%$ of households have an accumulation for an emergency case. $43.6 \%$ of households have a debt. These results reveal the vulnerability of poor households. 


\subsubsection{Mobility}

Mobility was associated with motor vehicle ownership, disability; elderly need in care, household's probability of meeting and property ownership outside the earthquake zone. $70.5 \%$ participants of households have no automobiles and $96.6 \%$ do not have motorcycles.

It is observed that in households where the mother of the family is a housewife, the level of probability of meeting increases both for students in the schools and members that are at work. For the most common case, the work place of the father is not reachable by walking from the house in $36 \%$ of cases.

\subsubsection{Community preparedness}

Community preparedness has an important part within the concept of social vulnerability (Morrow [4]). Community preparedness was examined with the aid of questions classified into four main groups (risk perception, risk reduction household-based, risk reduction sub-district based, solidarity).

The main themes associated with the title are as follows:

- $\quad$ Risk perception (earthquake forecast in Istanbul, condition of residential building, earthquake loses, earthquake preparedness)

- $\quad$ Risk reduction - household based (building reinforcement, building construction year, earthquake experience, behavior during earthquake, earthquake knowledge, NGO membership, prevention taken against an earthquake, the distance between business, school and home)

- Solidarity (sub-district life span, relations of the people living in the neighborhood)

- Sub-district based risk reduction (earthquake drill, emergency action plan, reinforced education facility, reinforced health facility, temporary shelter).

$15.9 \%$ of the survey respondents believe that there is no expectation of an earthquake in Istanbul. $51.7 \%$ of the subjects think that there could be an earthquake at any moment or in the near future. $24.8 \%$ of respondents believe that the earthquake would damage their house.

$67.3 \%$ of participants consider that an expected earthquake in Istanbul will destroy lots of buildings and many people will lose their lives. 37.2\% of survey respondents think that there will be no damage to their house and $83.4 \%$ of respondents are not prepared for an earthquake. $8.1 \%$ of the participants' buildings were reinforced. In $64 \%$ of the households, there is no reinforcement in their buildings.

Disaster preparedness of a community requires actions at an individual, social and institutional level. Thus, while evaluating the preparedness concept, all these three aspects must be considered. With this perspective, 48 sub-district chief officers were interviewed and 47 of the interviews were taken into account. 1 of the interviews was interrupted and cut half by the officer himself. But the results show that a significant proportion $(36 \%)$ of the officers declare that public institutions must be in contact with them and they must show guidance to the public to reduce earthquake risks. $36 \%$ state that there are volunteer groups and equipment depots where first response kits are preserved. Only $21 \%$ of them 
indicated that there is an actual or at least draft emergency plan for the aftermath of a disaster. It was also observed that rapid change in urban structure and population causes lack or loss of information about the neighborhood.

\section{Social vulnerability analysis}

As stated above, there are various indicators related with social vulnerability and in the household survey, the gathered data included more than was needed. This was a result of a precaution to avoid any lack of information that has to be acquired from the field.

After these indicators are identified, first of all, each indicator is embedded in the LDW database and numbers filtered from the survey have been put in software.

Following the database creation, all sub-indicators are normalized between 0 and 1 where 0 indicates minimum, 1 indicates maximum level of vulnerability. This enables us to evaluate different types of indicators with each other and compare them. Normalization is done based on the assumption that as the level of numbers in the database increases so does the level of social vulnerability. It must be noted that there are different types of relationships between these values and vulnerability. In this study, a linear and directly proportional relationship is taken into account.

After the normalization process, the main indicators are weighted based on the expert reviews. Each expert was given a weighting questionnaire comparing the relative importance of 7 main indicators. The reason behind weighting only the main indicators is to protect the consistency of the analysis; where consistency decreases as the number of compared indicators increase.

According to weighting, the importance percentage of indicators is calculated as shown in Table 4.

Table 4: Weights of indicator.

\begin{tabular}{|l|c|}
\hline INDICATOR & WEIGHT (\%) \\
\hline Disability and special treatment & $25.9 \%$ \\
\hline Access to health facilities & $21.7 \%$ \\
\hline Mobility & $14.9 \%$ \\
\hline Economic structure & $13.3 \%$ \\
\hline Community preparedness & $10.7 \%$ \\
\hline Demographic structure & $5.4 \%$ \\
\hline Solidarity & $5.2 \%$ \\
\hline Education & $2.8 \%$ \\
\hline
\end{tabular}

\section{Results and discussion}

As a result, each indicator is compared with each other based on their amount and weights within a normalized scale (Figure 5). 


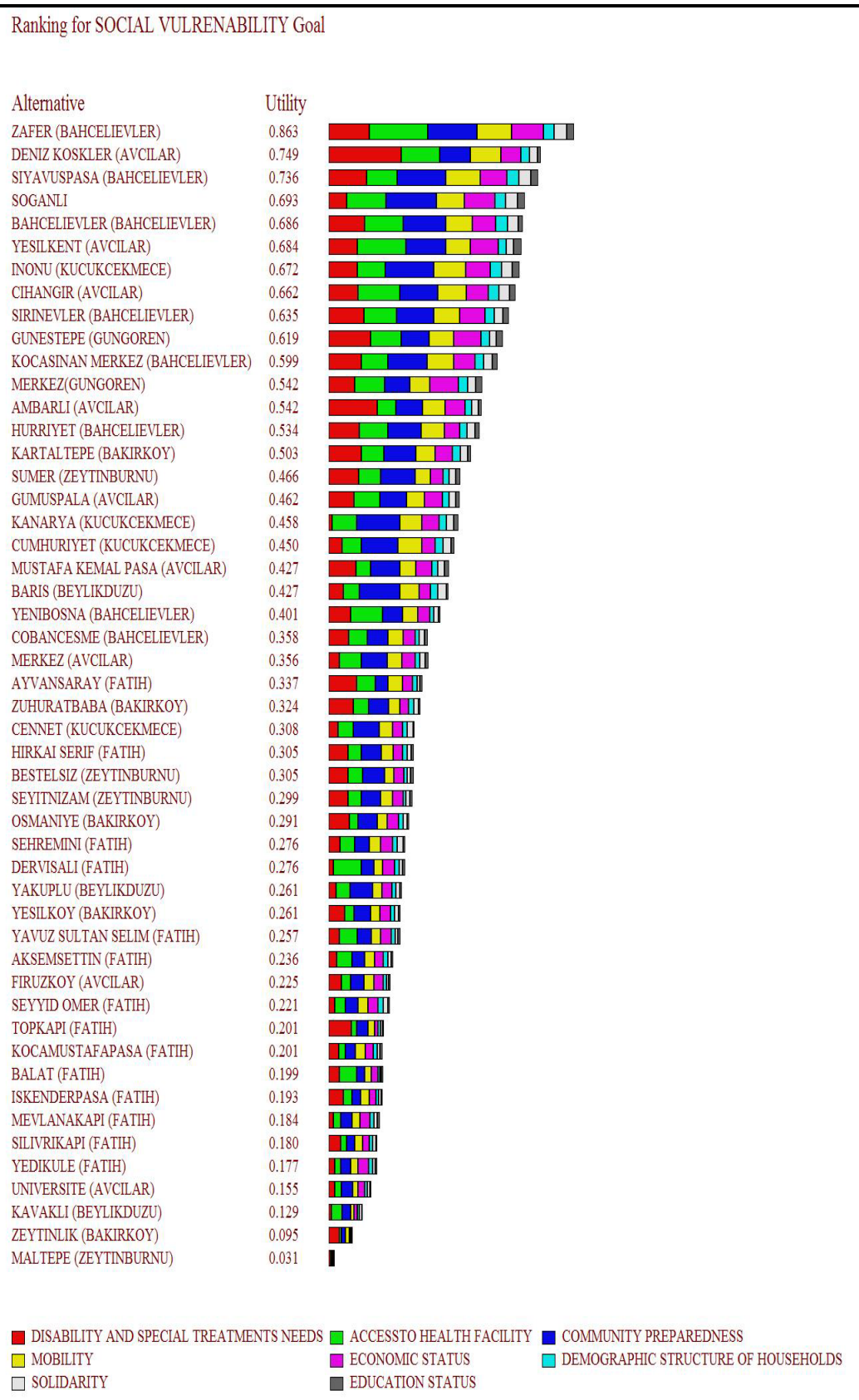

Figure 5: Ranking of sub-districts based on their social vulnerability scores. 
At the end of the study, the vulnerability analysis shows that the people in the study area are mostly affected by their health structure both in terms of their household structure (disability and/or special treatment) and their access to health facilities. It is also seen that community preparedness plays an important role for understanding the level of social vulnerability.

The methodology used here is useful by means of integrating different types of indicators into one scale in a comparative manner. The data is especially important for decision makers to prioritize their actions to reduce the level of social vulnerability and increase the level of resiliency. Moreover, the index gives opportunity on which indicator must be dealt with more importance. For instance, disability may be irrelevant for a sub-district while in others it can be the most important theme for risk reduction activities. Another point is that, as social vulnerability is assumed to increase the level of seismic risk by creating cascading effects in the aftermath of a disaster; decision makers must consider these results to enhance their preparation and risk prevention actions.

In addition, it is observed that people are mostly concerned with the phenomenon of an earthquake and although their level of risk perception or reduction is low they are quite aware of the problem. But, because lack of knowledge for acting against it and of the mainstreaming of knowledge from public institutions to a community level are seen as the primary causes of this situation. Moreover, sub-district chief officers (muhtars) are seen to be very active in the field (at the most local level) and their knowledge about their neighborhood must benefit developing proper actions and their active participation in risk reduction activities must be provided. By this, public participation will be stimulated and the sustainability of DRR actions will be guaranteed.

\section{Acknowledgements}

The authors of this paper would like thank the Istanbul Development Agency for supporting this project financially, Istanbul Metropolitan Municipality and the Director of Earthquake and Ground Research Mr. Mahmut BAS for providing physical and administrative conditions and Prof. Sibel Kalaycioğlu, Prof. Eser Çaktı, Assoc. Prof. Burçay Erus and Disaster Risk Management Specialist Bilgen Sungay for their technical assistance and consultations during the household surveys.

\section{References}

[1] Wisner, B., Blaikie, P., Cannon \& T., Davis, I., At Risk, Natural Hazards and People's Vulnerability and Disasters, http://www.preventionweb.net /files/670_72351.pdf, 2003. Geography, 20(4): 529-39, 1996.

[2] Cutter, S. L., Boruff, B.J.W., Shirley, L., Social Vulnerability To Environmental Hazards, Social Science Quarterly, 84(2), 2003. 
24 Disaster Management and Human Health Risk IV

[3] Evans, G. W. \& Kantrowitz, E., Socioeconomic Status and Health: The Potential Role of Environmental Risk Exposure, Annu Rev Public Health, 23: 303-31, 2002.

[4] Morrow, B.H., Identifying and Mapping Community Vulnerability, Disasters 23: 1-18, 1999. 